\title{
Classifications of Adenomyosis and Correlation of Phenotypes in Imaging and Histopathology to Clinical Outcomes: a Review
}

\author{
Tina Tellum ${ }^{1}\left[\right.$ : Malcolm G. Munro ${ }^{2}(0$ \\ Accepted: 10 December 2021 / Published online: 7 February 2022 \\ (c) The Author(s) 2022
}

\begin{abstract}
Purpose of Review To provide an update on published classification and reporting systems for adenomyosis. There is an urgent need to standardize reporting of various phenotypes of adenomyosis into a validated and globally recognized system. This can be used to examine the nature and severity of adenomyosis symptoms and inform the design, evaluation, and implementation of appropriate treatment options.

Recent Findings In recent years, several new proposals for adenomyosis classification have emerged. Most are MRI-based and include features such as uterine size, junctional zone thickness, size and location of the lesions, and distribution patterns. To date, none of those proposals has been validated. Only one recent classification based on transvaginal ultrasound was validated for interobserver congruence and correlated to clinical findings. However, the differentiation of diffuse and focal adenomyosis still lacks consensus. In addition, only a few authors advocated imaging-based definitions.

Summary There is a need for one or a combination of a classification and reporting system for adenomyosis. To date, there is no widely accepted and validated system.
\end{abstract}

Keywords Adenomyosis $\cdot$ Classifications $\cdot$ Imaging $\cdot$ Histopathology $\cdot$ Pathophysiology

\section{Introduction}

In medicine, several disorders and conditions are poorly or incompletely understood. They might have a variety of imaging, molecular or other clinical features. Such circumstances beg for creating systems of categorization, or "classification," that support clinical care, patient and trainee education, and the performance of basic, translational, clinical, and epidemiological research. At a scientific level, a classification system can serve to identify categories of a disorder that allows for the comparison of outcomes between different investigators by facilitating systematic review and

This article is part of the Topical Collection on Uterine Fibroids and Endometrial Lesions

Tina Tellum

tina.tellum@gmail.com

1 Department of Gynecology, Oslo University Hospital Trust, Oslo, Norway

2 Department of Obstetrics \& Gynecology, David Geffen School of Medicine, UCLA/Kaiser Permanente Los Angeles Medical Center, Los Angeles, CA, USA meta-analysis. From a clinical perspective, classification or categorization can aid diagnosis, prognosis, or inform the selection of management options ranging from expectant to a spectrum of medical and procedural options. Classifications can be based on phenotypical traits including imaging, histopathology, genetic markers, or molecular characteristics.

Despite the first published description of adenomyosis in 1860 [1], understanding of pathogenesis, prevalence, clinical relevance, ideal diagnostic techniques, and appropriate and effective management of adenomyosis remain unclear. Historically, adenomyosis is diagnosed by histopathology of hysterectomy specimen. Diagnosing adenomyosis by myometrial biopsy is impractical and suboptimal. Today, imaging techniques are relatively accurate for the detection of adenomyosis. Yet, there is a lack of standardization [2-4]. While there are several proposed systems, none has been universally adopted - a circumstance that is problematic for both clinicians and investigators and the patients $[2,5]$.

Sonographic features of adenomyosis have been reported in about $21-34 \%$ of women attending gynecology clinics $[6 \bullet \bullet, 7]$. The clinical relevance of the disorder has been limited to the two best-known symptoms, which are heavy menstrual bleeding (HMB) and dysmenorrhea [8]. Recent 
studies suggest that adenomyosis may be associated with adverse effects on fertility and might contribute to obstetrical complications, such as preterm labor, fetal growth restriction, and preeclampsia [9-11].

The purpose of our review was to identify and compare studies evaluating adenomyosis features and their clinical relevance, as well as describe classification systems for adenomyosis, based on one or a combination of clinical, phenotypical, histological, molecular, or genetic features. Furthermore, we evaluated studies that assess adenomyosis features and those that correlate a classification or individual characteristics to clinical outcomes.

\section{Diagnostic Classifications}

We identified 10 manuscripts describing a histological diagnostic classification system. Six are based on the diagnosis on the depth of myometrial involvement [12-17], two on the proportion of myometrium involvement [18, 19], and two others use other features [20,21]. For ultrasound a system of terminology for categorizing and describing sonographic features associated with adenomyosis was presented by experts in the so-called Morphological Uterus Sonographic Assessment (MUSA) statement [22••]. This system is currently the most recognized and widely used ultrasound classification of adenomyosis. For magnetic resonance imaging (MRI), several diagnostic accuracy studies were published; however, the consensus is still lacking [23].

\section{Disease Classifications}

\section{Histopathology}

Identified histology-based classifications are shown in Table $1[13-17,19,21,24-26]$. They focus primarily on disease location or extent. While phenotypical features such as muscular hypertrophy or hyperplasia were described, these were not used as markers in these classifications.

\section{MRI-Based Systems}

Table 2 shows the MRI-based systems using a spectrum of criteria [2, 5, 27•, 28-30]. An early proposal from Kishi et al. distinguished four subtypes of adenomyosis based on the myometrial region involved: subtype I-intrinsic (inner myometrium), subtype II—extrinsic (outer myometrium), subtype III-intramural (surrounded by normal outer myometrium), and subtype IV-indeterminate (not fit into any of the other types) [27•]. The authors concluded that the pathogenesis of these different phenotypes might vary from the concept of myometrial invasion of heterotopic endometrium. Yet, it does not explain the mechanism of subtypes II and III. This classification has since been adapted and modified by many authors. A similar layered concept has been included in the Bazot system [30], which further distinguishes anterior from posterior involvement as well as disease volume and patterns (Table 2).

While all other systems are purely based upon MRI characteristics, Grimbizis et al. added endometrial finding of a polypoid adenomyoma confirmed by histopathology [5].

Several authors postulated that adenomyosis in the outermost aspect of the myometrium ("extrinsic" type) may originate from endometriosis involving the myometrium by "invasion" through the serosa [29, 31-34]. However the extrinsic type is frequently found in women without endometriosis [29]. Since it is difficult to reliably determine the origin of the findings at least by imaging we conclude that "extrinsic" adenomyosis should not be classified as a subtype of endometriosis.

\section{Ultrasound-Based Systems}

We identified two studies describing classifications based on transvaginal ultrasound (Table 2) [34-36]. In a consensus work, the MUSA statement [22••] was later modified to allow the description of findings stratified by anterior and posterior location and by involvement with one or more of three arbitrarily defined myometrial layers [35].

Lazeri et al. proposed a system combining the pattern (diffuse adenomyosis, focal adenomyosis, or adenomyoma) with location based on a more "anatomic" two-layer myometrium (inner or outer myometrium) and a grade of disease (severity score 1-4) (Table 2) [36]. The inter-rater reproducibility of this system has been internally validated and found to be suitable for clinical use. In a second publication, this system was correlated with clinical symptoms [34].

\section{Others}

Gordts et al. proposed an imaging-based classification that could be used with either MRI or ultrasound [37]. The authors proposed identifying the affected myometrial layer (inner or outer myometrium), the location (anterior, posterior, or fundus), the pattern (diffuse or focal, if focal specified as muscular or cystic), and disease volume.

\section{Adenomyosis Imaging Features and Correlation to Clinical Outcomes}

Study characteristics and detailed results of the included studies are shown in Table 3. 
Table 1 Histopathological adenomyosis classification systems

\begin{tabular}{|c|c|c|c|c|}
\hline \multirow[t]{2}{*}{ Author, year } & \multicolumn{2}{|l|}{ Category } & \multicolumn{2}{|l|}{ Pattern } \\
\hline & Name & Depth & Name & Foci \\
\hline \multirow[t]{3}{*}{ Sampson [21] } & Group 1 & Invasion from within & N/A & N/A \\
\hline & Group 2 & Invasion from without & N/A & N/A \\
\hline & Group 3 & Adenomyoma (intramyometrial) & N/A & N/A \\
\hline \multirow[t]{3}{*}{ Bird et al. [13] } & Grade I & Sub-endometrial basalis & Mild & $1-3$ foci/LPF \\
\hline & Grade II & Mid-myometrium & Moderate & $4-9$ \\
\hline & Grade III & Outer myometrium & Severe & $\geq 10$ \\
\hline \multirow[t]{2}{*}{ Nishida et al. [24] } & Type 1 & Continuous from endometrium & N/A & Islands/section \\
\hline & Type 2 & Continuous from serosa & N/A & Glands/section \\
\hline \multirow[t]{2}{*}{ McCausland [25] } & Superficial & $\leq 1 \mathrm{~mm}$ depth & N/A & N/A \\
\hline & Deep & $>1 \mathrm{~mm}$ depth & N/A & N/A \\
\hline \multirow[t]{3}{*}{ Siegler et al. [19] } & Grade 1 & Inner $1 / 3$ & Mild & $1-3$ foci/LPF \\
\hline & Grade 2 & $2 / 3$ & Moderate & $4-9$ \\
\hline & Grade 3 & Entire myometrium & Severe & $\geq 10$ \\
\hline \multirow[t]{3}{*}{ Levgur et al. [14] } & Superficial & $<40 \%$ & N/A & Foci/LPF \\
\hline & Intermediate & $40-80 \%$ & N/A & N/A \\
\hline & Deep & $>80 \%$ & N/A & N/A \\
\hline \multirow[t]{4}{*}{ Sammour et al. [15] } & N/A & $<25 \%$ & N/A & Foci/slide \\
\hline & N/A & $26-50 \%$ & N/A & N/A \\
\hline & N/A & $51-75 \%$ & N/A & N/A \\
\hline & N/A & $>75 \%$ & N/A & N/A \\
\hline \multirow[t]{3}{*}{ Hulka et al. [16] } & Mild & Inner 1/3 (or microscopic foci) & N/A & N/A \\
\hline & Focal & Adenomyoma & N/A & N/A \\
\hline & Severe/diffuse & Outer $2 / 3$ (include entire myometrium) & N/A & N/A \\
\hline \multirow[t]{3}{*}{ Vercellini et al. [3] } & Mild & Up to $1 / 3$ & Grade 1 & $1-3$ islets \\
\hline & Moderate & $1 / 3$ to $2 / 3$ & Grade 2 & $4-10$ islets \\
\hline & Severe & $>2 / 3$ & Grade 3 & $>10$ islets \\
\hline \multirow[t]{3}{*}{ Rasmussen et al. [26] } & Intrinsic & $\begin{array}{l}\geq 2 \mathrm{~mm} \text { myometrial invasion without contact to the basal } \\
\text { endometrium }\end{array}$ & & \\
\hline & Serrated junctional zone & $\begin{array}{l}>3 \mathrm{~mm} \text { myometrial invasion with contact to the basal endo- } \\
\text { metrium (precursor of adenomyosis) }\end{array}$ & & \\
\hline & Linear junctional zone: & $\begin{array}{l}\text { No or marginal myometrial invasion } \leq 3 \mathrm{~mm} \text { with contact to } \\
\text { the basal endometrium }\end{array}$ & & \\
\hline
\end{tabular}

\section{Disease Distribution: Diffuse vs. Focal}

Three studies found that women with diffuse adenomyosis were older [7, 8, 34] and suffered more frequently from HMB [34] than those with focal disease. There was no association of the diffuse type with dysmenorrhea in one study [34], while such a relationship was found in another [8]. Pinzauti et al. showed that diffuse adenomyosis was associated with a higher average symptom burden than women without adenomyosis. However, in this population, no focal type adenomyosis was described [7].

Women with focal findings had a higher risk of infertility and miscarriage in one study [34]. This relationship was also found in a study published by Bourdon et al. [38]. Tamura et al. reported no elevated risk of miscarriage [39].

\section{Disease Location: Inner, Middle Outer Myometrium}

The terms "inner adenomyosis," "intrinsic adenomyosis," or "JZ disease" are often interchangeably used. Kishi et al. found no difference in pain scores (dysmenorrhea, dyspareunia, or CPP) or HMB based on the location within the myometrium [27•]. Naftalin et al. showed that an irregular JZ was significantly associated with higher pain scores for dysmenorrhea [40].

Iwasawa et al. showed that the location of the adenomyotic lesion did not affect the clinical pregnancy rate in a cohort undergoing embryo transfer [41]. Still, the extrinsic group had fewer pregnancy losses [41]. In a retrospective study, Bourdon showed that infertility was related to focal findings in the outer myometrium but not to diffuse internal 
Table 2 Imaging-based adenomyosis classification and grading systems. MRI magnetic resonance imaging. JZ junctional zone

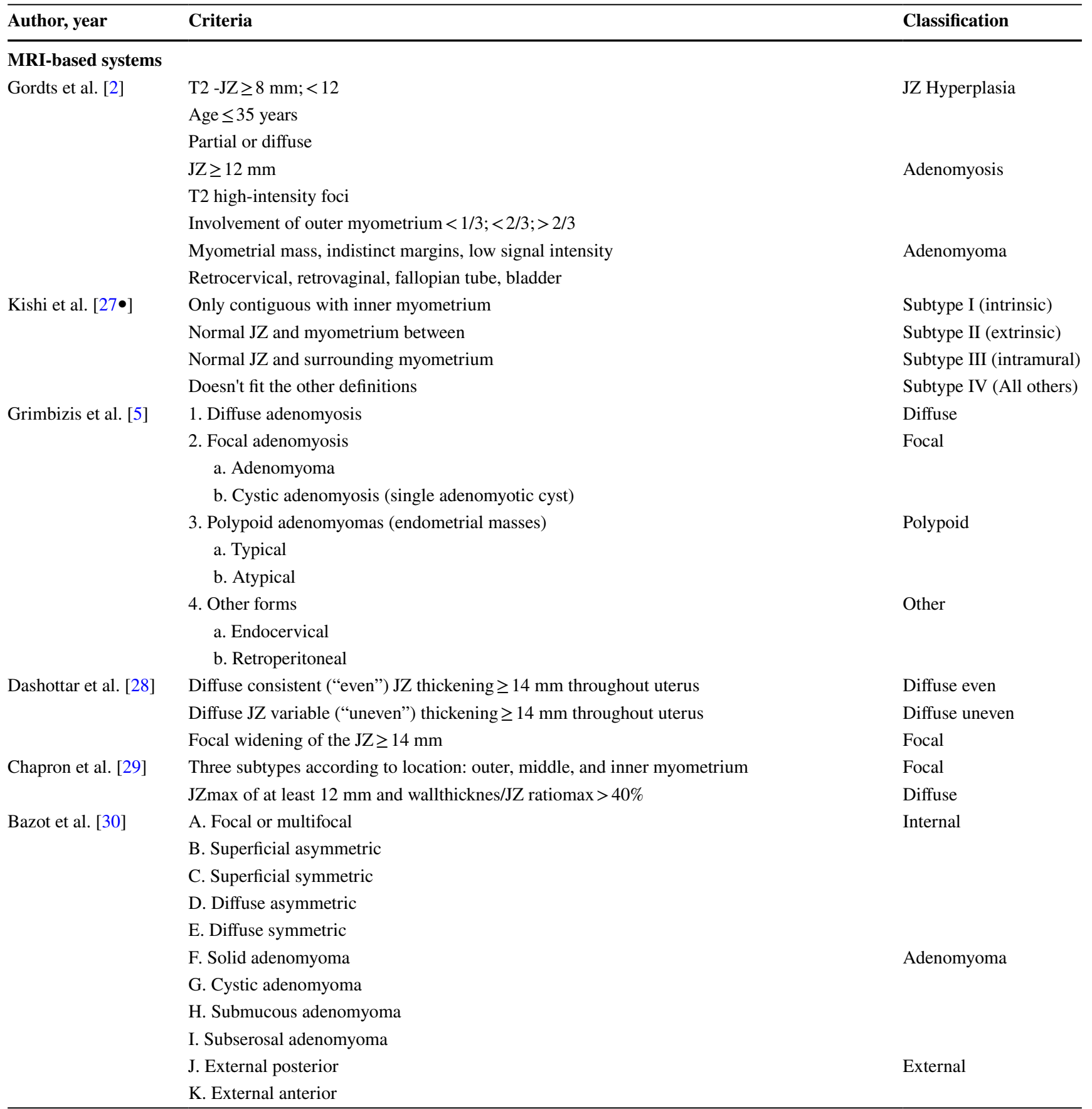

\section{Transvaginal ultrasound-based systems}

Van den Bosch et al. [35] Presence of diagnostic signs

Location: anterior posterior lateral left lateral right fundal

diffuse, focal ( $>25 \%$ surrounded by normal myometrium), mixed, adenomyoma

Measurable, size of the largest lesion

Inner: Type 1

Middle (inner to vascular arcade): Type 2

Outer: (vascular arcade to serosa): Type 3

Multi-layer: (type 1-2, 2-3, or 1 to 3 )
Location

Differentiation

Cystic-non-cystic

Layer 
Table 2 (continued)

\begin{tabular}{|c|c|c|}
\hline Author, year & Criteria & Classification \\
\hline & Mild: $<25 \%$ & Extent \\
\hline & Moderate: $25-50 \%$ & \\
\hline & Severe: $>50 \%$ & \\
\hline & Focal: plane of largest diameter of largest lesion & Size \\
\hline & Diffuse: myometrial thickness & \\
\hline \multirow[t]{18}{*}{ Exacoustos et al. [34] } & Score 1: single myometrial wall involvement with thickness $\leq 20 \mathrm{~mm}$ & Diffuse outer \\
\hline & Score 2: double myometrial wall involvement with thickness $\geq 20 \mathrm{~mm}$ or & \\
\hline & Single myometrial wall involvement with thickness $\geq 20-\leq 30 \mathrm{~mm}$ & \\
\hline & Score 3: single myometrial wall involvement with thickness $\geq 30 \mathrm{~mm}$ or & \\
\hline & double myometrial wall involvement with thickness $\geq 20-\leq 30 \mathrm{~mm}$ & \\
\hline & $\begin{array}{l}\text { Score 4: Double myometrial wall involvement with thickness } \geq 30 \mathrm{~mm} \text { or whole uterus } \\
\text { involved with global enlargement }\end{array}$ & Diffuse inner \\
\hline & Score 1: JZmax $\geq 6-\leq 8 \mathrm{~mm}$ or diffuse infiltration of the $\mathrm{JZ} \leq 20 \mathrm{~mm}$ in length & \\
\hline & $\begin{array}{l}\text { Score 2: JZmax } \geq 8 \mathrm{~mm} \text { or diffuse infiltration of the } \mathrm{JZ} \leq 20 \mathrm{~mm} \text { in length or } \leq 50 \% \text { of the } \\
\text { uterus }\end{array}$ & \\
\hline & Score 3: diffuse infiltration of the $\mathrm{JZ} \geq 50 \% \leq 80 \%$ of the uterus & \\
\hline & Score 4: diffuse infiltration of the $\mathrm{JZ} \geq 80 \%$ of the uterus & \\
\hline & Score 1: One focal intramyometrial lesion $<10 \mathrm{~mm}$ & Focal outer \\
\hline & $\begin{array}{l}\text { Score } 2: \geq 2 \text { intramyometrial lesions }<10 \mathrm{~mm} \text { or one focal intramyometrial lesion of } \\
10-20 \mathrm{~mm}\end{array}$ & \\
\hline & $\begin{array}{l}\text { Score } 3: \geq 2 \text { intramyometrial lesions } 10-20 \mathrm{~mm} \text { or one focal intramyometrial lesion } \\
\text { of }>20 \mathrm{~mm}\end{array}$ & \\
\hline & Score $4: \geq 2$ intramyometrial lesions $>20 \mathrm{~mm}$ or $\geq 3$ focal intramyometrial lesions & \\
\hline & Score 1: One focal lesion in JZ or cystic areas $\leq 10 \mathrm{~mm}$ & Focal inner \\
\hline & Score $2: \geq 2$ focal lesions of the $\mathrm{JZ} \leq 10 \mathrm{~mm}$ or one focal intramyometrial lesion of $10-20 \mathrm{~mm}$ & \\
\hline & Score $3: \geq 2$ focal lesions of the $\mathrm{JZ} 10-20 \mathrm{~mm}$ or one focal lesion of the $\mathrm{JZ}$ of $>20 \mathrm{~mm}$ & \\
\hline & Score $4: \geq 2$ focal lesions of the $\mathrm{JZ}>20 \mathrm{~mm}$ or $\geq 3$ focal lesions of the $\mathrm{JZ}$ & \\
\hline
\end{tabular}

adenomyosis. They defined adenomyosis as a JZ $12 \mathrm{~mm}$ or more in thickness and involving at least $40 \%$ of the total myometrial thickness [38]. These findings appear to be in contrast to a prospective study from Maubon et al. that demonstrated that embryo transfer failure was more common when the mean JZ thickness was more significant than $7 \mathrm{~mm}$ and the maximum thickness more than $10 \mathrm{~mm}$ [42].

\section{Disease Pattern: Cystic vs. Hypertrophic}

Role of disease patterns in clinical manifestations is unclear. Naftalin et al. found that the presence of myometrial cysts was not explicitly associated with a higher dysmenorrhea score [43]. Hemorrhagic lesions that can be discriminated from cysts without hemorrhage in T1-weighted MRI were more frequently found in intrinsic or extrinsic adenomyosis when compared to isolated adenomyosis in the middle myometrium [27•]. Yet, the number of cases was relatively small and involved a selected group of women. Bourdon et al. found no association between infertility and the presence of bright spots on T2 [38].
Several investigators have correlated MRI-based signal intensity (T2 hyperintense foci or T1 lesion signal) to the success of high-intensity focused ultrasound (HIFU) therapy [44-47]. These studies suggest that the relative amounts of glands and stroma in the adenomyotic mass can impact the results of hyperthermic treatment-at least based on the imaging outcomes.

\section{Volumetric Relationships: Lesion Size and Disease Extent}

Bird et al. studied the association between depth of adenomyosis involvement and symptoms. They found no relationship with recorded bleeding symptoms, but they demonstrated that the number of "islets" of adenomyotic glandular tissue per low powered field was proportional to the subjectively determined volume of menses [13]. Similar findings were described by Sammour et al. and Rasmussen et al., who also reported no relationship between depth of myometrial involvement and the symptom of HMB [15, 26]. However, Rasmusen et al. reported that symptom improvement after 


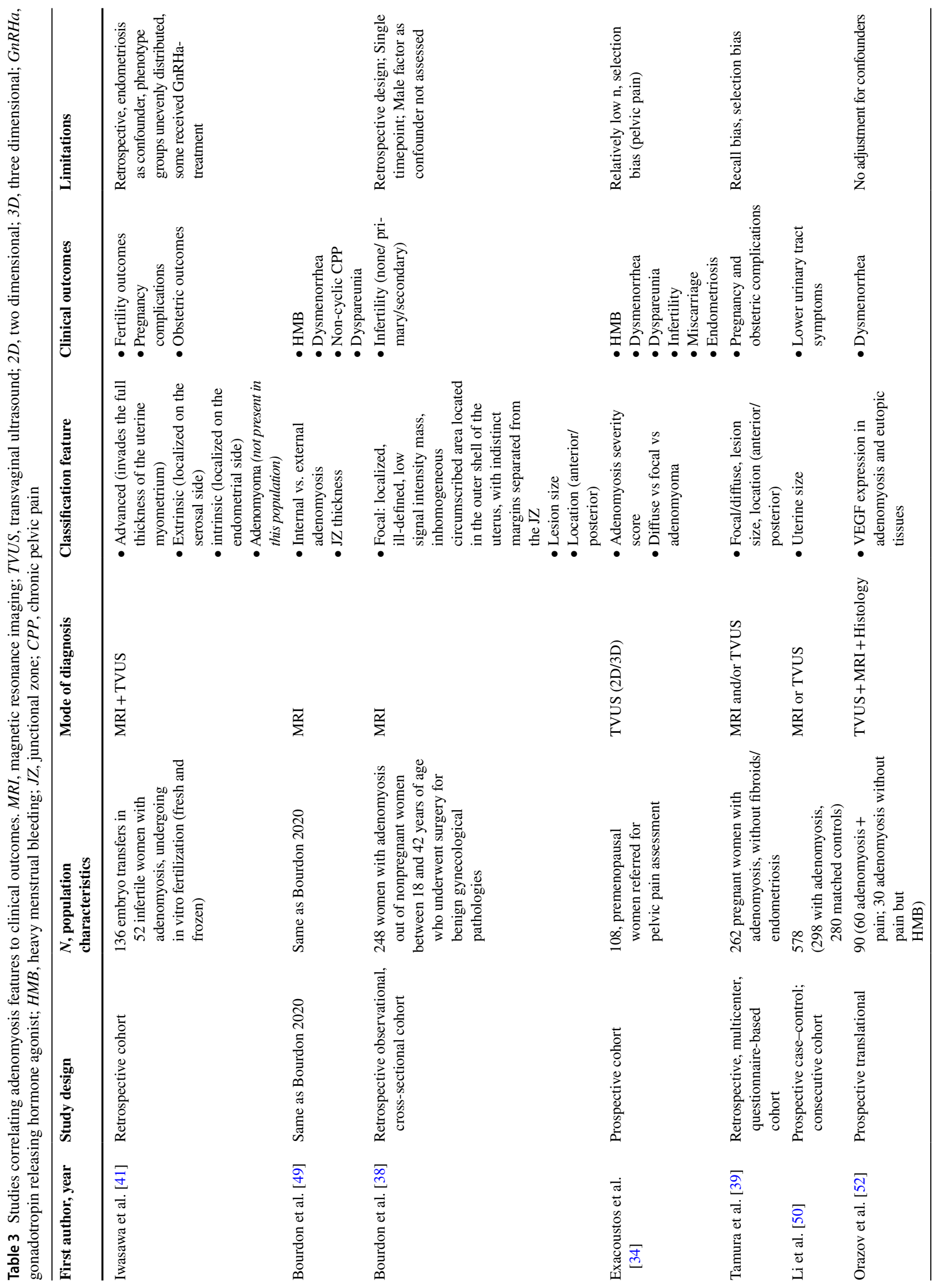




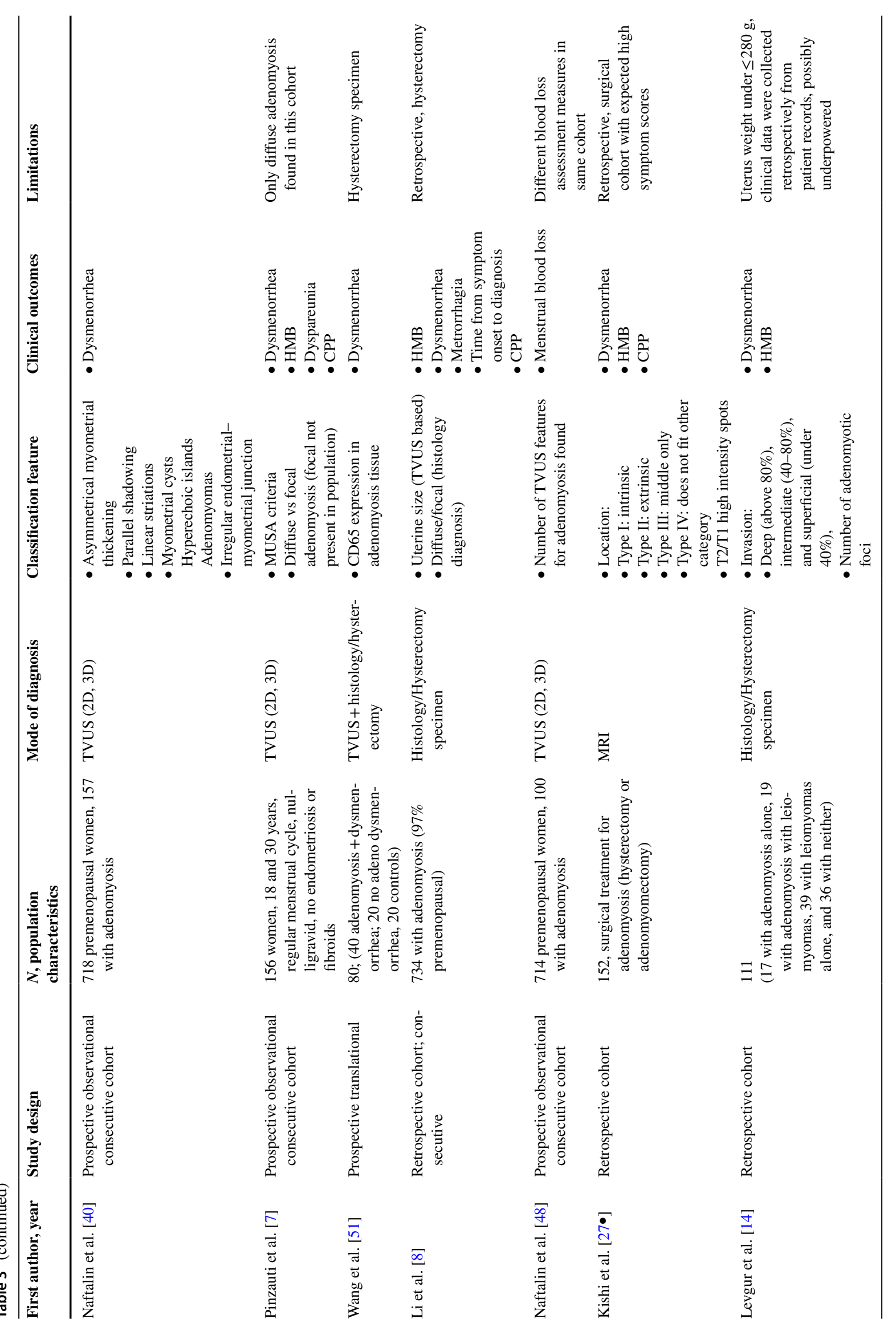


transcervical endometrium resection was greater with minimal depth of involvement of the myometrium [26].

The outlier in this group of studies is the report by Levgur et al., where the symptom of HMB was $36.8 \%$ in women with deep foci and $13.3 \%$ in those with "intermediate" depth foci [14]. Sammour et al., who evaluated dyspareunia and "other pain" found a poor correlation with depth, but again, there was a correlation with the number of foci identified histopathologically. A few authors reported a correlation between depth of adenomyosis involvement as well as the number or volume of foci of glandular tissue and dysmenorrhea [13, 14, 24].

Naftalin et al. and Pinzauti et al. reported a linear relationship between ultrasound diagnosis of adenomyosis and dysmenorrhea and HMB symptom severity [7, 40, 48].

\section{Volumetric Relationships}

\section{Lesion Volume}

Estimated adenomyosis volume and clinical manifestations have been examined by Exacoustos et al. who showed that symptom severity was associated with disease severity mainly based on lesion size and \%-involvement of the myometrium [34]. However, it seems that the size of an adenomyoma, defined as a subgroup of focal adenomyosis surrounded by hypertrophic myometrium, is not associated with more pain, as demonstrated in two studies [34, 48]. There have been early evaluations of the volume of adenomyosis findings and pregnancy outcomes. Tamura et al. found the rates of miscarriage and cervical insufficiency were higher in the group with large lesions [39].

\section{Uterine Volume}

Another feature associated with adenomyosis, and indirectly, with disease volume, is uterine volume. Li et al. showed that large uterine size was independently associated with bothersome lower urinary tract symptoms (LUTS) and HMB, but not dysmenorrhea or chronic pelvic pain (CPP) [50]. Another group showed that smaller uteri were associated with more CPP (8). Disease duration and age were also positively associated with the uterine size, supporting the progressive nature of adenomyosis.

\section{Molecular Markers}

An evolving approach to evaluating the potential impact of adenomyosis is using molecular markers, not only for diagnosis but also as instruments to monitor response to therapeutic interventions. Wang showed that CD65 expression was higher in women with dysmenorrhea than those without dysmenorrhea and controls [51]. The same association was also found for VEGF expression and dysmenorrhea [52]. VEGF was found in hypertrophic muscular bundles
[52]. Bourdon et al. correlated MRI findings with serum cytokine profiles. They found that in women with both focal and diffuse adenomyosis, the levels of IL-23, IL-25, IL-31, and IL-33 were lower than in controls. The levels of IL-17F levels were lower in women with focal adenomyosis than in controls. TNF $\alpha$ levels were lower in women with focal disease compared to those with diffuse adenomyosis [53].

\section{Discussion}

Adenomyosis is a disorder of increasing interest, in part because of its newfound high prevalence on ultrasonic and magnetic resonance imaging and in part because of its variable impact on clinical outcomes such as infertility, pelvic pain, abnormal uterine bleeding, and pregnancy-related disorders. It is still unclear how imaging features of adenomyosis correlate to symptoms or other adverse outcomes such as infertility or pregnancy loss. There exists an urgent need, at least for a standardized reporting system to harmonize the design and interpretation of basic science and clinical investigation as well as education and clinical care.

In this review, we found various reporting or classification systems based on histopathological, MRI, or TVUS features. While most systems are designed to include the location, the extent, and the distribution pattern of adenomyosis features (focal or diffuse), few describe more specific phenotypical patterns such as the presence, size, or types of cysts, or the location and extent of findings suggesting the presence of muscular hyperplasia. We identified studies that correlated clinical findings with phenotypical traits of adenomyosis, suggesting that a variety of features could be relevant in the design of a reporting or classification system.

There have been conflicting results regarding the clinical significance of the disease pattern (diffuse, focal, and adenomyoma). The differences in patient populations, the low number of participants in some studies, and the different definitions of those groups are likely the reason for these incongruencies. Also, as those traits are assessed by subjective pattern recognition, a high inter-rater variation is likely an important reason for these conflicting results.

The clinical significance of myometrial cysts (with and without hemorrhage) and muscular hyperplasia remains unclear. In a study investigating treatment response of high-intensity focused ultrasound (HIFU) in different phenotypes, the absence of T2 hyperintense spots in MRI was associated with an increased chance of nonperfusion and thus treatment response [45].

As a result of these considerations, it would seem prudent to include disease patterns in a reporting system. Such an approach would allow investigators to evaluate further the relationship of such findings to clinical manifestations of adenomyosis and characterize responses to various types of medical, ablative, and surgical therapy.

We found that the disease extent is likely to be linked to symptom severity. This was consistently shown in 
histopathological, MRI-based, and ultrasound-based studies. Furthermore, it was demonstrated that treatment efficacy depended on disease extent, which is not surprising $[26,44]$. These observations, along with the spectrum of disorder phenotypes, beg for evidence-based information to assist patients and clinicians in informed decision-making.

While the need for a uniform system for reporting should lead to a valuable classification of adenomyosis, it is equally apparent that such a system does not yet exist. We suggest that the research needed to obtain such information requires an accurate diagnosis and methods by which some composite of disease phenotype and molecular expressions are identified and documented. Categorizing the phenotype in a standardized fashion would allow for meaningful comparison of symptoms and clinical outcomes of medical and procedural interventions in patients with similar disease characteristics. It might lead to a better understanding of adenomyosis in a fashion sufficient to inform more tailored therapeutic approaches.

Imaging modalities are now widely accepted to be reliable tools and the first choice in diagnosing adenomyosis. Histopathology, while once the "gold standard" for diagnosing adenomyosis, requires extensive sections throughout the whole uterus to be reliable, which is not given in standard clinical practice [13, 54]. Furthermore, using a hysterectomy specimen introduces a selection bias that does not allow to draw conclusions on, for example, symptoms [55•].

Therefore, a classification and reporting system needs to be based on imaging. Previous reviews suggest that both MRI and ultrasound, as currently used, may have similar sensitivity and specificity for diagnosing adenomyosis [23]. As MRI potentially provides greater accuracy in determining disease volume, distribution, location, and pattern, it seems to be best suited to develop a classification system. However, as TVUS is widely available and either the only or the firstline tool in diagnosing adenomyosis, a universally useful classification needs to be applicable for ultrasound.

Assessment of molecular and genetic expressions, be they from serum, endometrial aspirates, or endometrial or myometrial biopsy specimens, may be necessary for determining the impact of adenomyosis in a given patient: a circumstance that may have particular importance in women with reproductive failure or who are planning to undergo embryo transfer. The place for such variables should be considered in the design of any system.

\section{Conclusions}

In summary, there is a need for a harmonized reporting system for both ultrasound and MRI that would allow performing research, which could be used to develop a disease classification system. In both reporting and classification systems, imaging modalities should take into account the histopathological features of the disorder. Fortunately, initiatives involving the international radiological and gynecological communities are underway. They are designed to achieve this goal so that clinicians, investigators, and especially patients will benefit from an increased understanding of this disorder.

Author Contribution The authors contributed equally to this manuscript.

Funding Open access funding provided by University of Oslo (incl Oslo University Hospital).

Availability of Data and Material (Data Transparency) All data is included in the manuscript.

Code Availability Not applicable.

\section{Compliance with Ethical Standards}

Ethics Approval Ethical approval was not necessary due to the nature of this work.

Consent to Participate Not applicable.

Conflict of Interest Dr. Tellum reports grants from South Eastern Norwegian Health Authority, personal fees from GE Healthcare, and personal fees from Medtronic, outside the submitted work. Dr Munro reports personal fees from Hologic, AbbVie, and Myovant as well as options held with Gynesonics Inc.

Human and Animal Rights and Informed Consent This article does not contain any studies with human or animal subjects performed by any of the authors.

Open Access This article is licensed under a Creative Commons Attribution 4.0 International License, which permits use, sharing, adaptation, distribution and reproduction in any medium or format, as long as you give appropriate credit to the original author(s) and the source, provide a link to the Creative Commons licence, and indicate if changes were made. The images or other third party material in this article are included in the article's Creative Commons licence, unless indicated otherwise in a credit line to the material. If material is not included in the article's Creative Commons licence and your intended use is not permitted by statutory regulation or exceeds the permitted use, you will need to obtain permission directly from the copyright holder. To view a copy of this licence, visit http://creativecommons.org/licenses/by/4.0/.

\section{References}

Papers of particular interest, published recently, have been highlighted as:

- Of importance

$\bullet$ Of major importance

1. von Rokitansky C. Über Uterusdrüsen-Neubildung. Z Gesellschaft Aerzte (Wien). 1860;16:577-81. 
2. Gordts S, Brosens JJ, Fusi L, Benagiano G, Brosens I. Uterine adenomyosis: a need for uniform terminology and consensus classification. Reprod Biomed Online. 2008;17(2):244-8.

3. Vercellini P, Vigano P, Somigliana E, Daguati R. Abbiati A. Fedele L Adenomyosis: epidemiological factors. 2006;20(4):465-77.

4. Benagiano G, Brosens I, Habiba M. Structural and molecular features of the endomyometrium in endometriosis and adenomyosis. Hum Reprod Update. 2014;20(3):386-402.

5. Grimbizis GF, Mikos T, Tarlatzis B. Uterus-sparing operative treatment for adenomyosis. Fertil Steril. 2014;101(2):472-87.

6.• Naftalin J, Hoo W, Pateman K, Mavrelos D, Holland T, Jurkovic D. How common is adenomyosis? A prospective study of prevalence using transvaginal ultrasound in a gynaecology clinic. Hum Reprod (Oxford, England). 2012;27(12):3432-9.

7. Pinzauti S, Lazzeri L, Tosti C, Centini G, Orlandini C, Luisi S, et al. Transvaginal sonographic features of diffuse adenomyosis in 18-30-year-old nulligravid women without endometriosis: association with symptoms. Ultrasound in obstetrics \& gynecology : the official journal of the International Society of Ultrasound in Obstetrics and Gynecology. 2015;46(6):730-6.

8. Li X, Liu X, Guo SW. Clinical profiles of 710 premenopausal women with adenomyosis who underwent hysterectomy. J Obstet Gynaecol Res. 2014;40(2):485-94.

9. Younes G, Tulandi T. Effects of adenomyosis on in vitro fertilization treatment outcomes: a meta-analysis. Fertil Steril. 2017;108(3):483-90.e3.

10. Horton J, Sterrenburg M, Lane S, Maheshwari A, Li TC, Cheong Y. Reproductive, obstetric, and perinatal outcomes of women with adenomyosis and endometriosis: a systematic review and meta-analysis. Hum Reprod Update. 2019;25(5):592-632.

11. Harada T, Taniguchi F, Amano H, Kurozawa Y, Ideno Y, Hayashi $\mathrm{K}$, et al. Adverse obstetrical outcomes for women with endometriosis and adenomyosis: a large cohort of the Japan Environment and Children's Study. PLoS One. 2019;14(8):e0220256.

12. Sandberg EC, Cohn F. Adenomyosis in the gravid uterus at term. Am J Obstet Gynecol. 1962;84:1457-65.

13. Bird CC, McElin TW, Manalo-Estrella P. The elusive adenomyosis of the uterus-revisited. Am J Obstet Gynecol. 1972;112(5):583-93.

14. Levgur M, Abadi MA, Tucker A. Adenomyosis: symptoms, histology, and pregnancy terminations. Obstet Gynecol. 2000;95(5):688-91.

15. Sammour A, Pirwany I, Usubutun A, Arseneau J, Tulandi T. Correlations between extent and spread of adenomyosis and clinical symptoms. Gynecol Obstet Invest. 2002;54(4):213-6.

16. Hulka CA, Hall DA, McCarthy K, Simeone J. Sonographic findings in patients with adenomyosis: can sonography assist in predicting extent of disease? 2002;179(2):379-83.

17. Vercellini P, Trespidi L, Panazza S, Bramante T, Mauro F, Crosignani PG. Laparoscopic uterine biopsy for diagnosing diffuse adenomyosis. The J Reprod Med. 1996;41(4):220-4.

18. Ferenczy A. Pathophysiology of adenomyosis. Hum Reprod Update. 1998;4(4):312-22.

19. Siegler AM, Camilien L. Adenomyosis. J Reprod Med. 1994;39(11):841-53.

20. Uduwela AS, Perera MA, Aiqing L, Fraser IS. Endometrialmyometrial interface: relationship to adenomyosis and changes in pregnancy. Obstet Gynecol Surv. 2000;55(6):390-400.

21. Sampson JA. Perforating hemorrhagic (choclate) cysts of the ovary: Their importance and especially their relation to pelvic adenomas of endometrial type ("Adenomyoma" of the uterus, rectovaginal septum, sigmoid, etc.). Arch Surg. 1921;3(2):245-323.

22.•• Van den Bosch T, Dueholm M, Leone FP, Valentin L, Rasmussen CK, Votino A, et al. Terms, definitions and measurements to describe sonographic features of myometrium and uterine masses: a consensus opinion from the Morphological Uterus Sonographic Assessment (MUSA) group. Ultrasound Obstet Gynecol. 2015;46(3):284-98.
23. Tellum T, Nygaard S, Lieng M. Noninvasive diagnosis of adenomyosis: a structured review and meta-analysis of diagnostic accuracy in imaging. J Minim Invasive Gynecol. 2019.

24. Nishida M. Relationship between the onset of dysmenorrhea and histologic findings in adenomyosis. Am J Obstet Gynecol. 1991;165(1):229-31.

25. McCausland AM. Hysteroscopic myometrial biopsy: its use in diagnosing adenomyosis and its clinical application. Am J Obstet Gynecol. 1992;166(6 Pt 1):1619-26; discussion 26-8.

26. Rasmussen CK, Hansen ES, Al-Mashadi Dahl S, Ernst E, Dueholm $M$. The effect of transcervical endometrial resection on clinical symptoms related to intrinsic adenomyosis and junctional zone changes. Eur J Obstet Gynecol Reprod Biol X. 2019;3:100029.

27.• Kishi Y, Suginami H, Kuramori R, Yabuta M, Suginami R, Taniguchi F. Four subtypes of adenomyosis assessed by magnetic resonance imaging and their specification. Am J Obstet Gynecol. 2012;207(2):114.e1-7.

28. Dashottar S, Singh AK, Debnath J, Muralidharan CG, Singh RK, Kumar S. Comparative analysis of changes in MR imaging of pre and post intrauterine progesterone implants in adenomyosis cases. Med J Armed Forces India. 2015;71(2):145-51.

29. Chapron C, Tosti C, Marcellin L, Bourdon M, Lafay-Pillet MC, Millischer AE, et al. Relationship between the magnetic resonance imaging appearance of adenomyosis and endometriosis phenotypes. Hum Reprod. 2017;32(7):1393-401.

30. Bazot M, Darai E. Role of transvaginal sonography and magnetic resonance imaging in the diagnosis of uterine adenomyosis. Fertil Steril. 2018;109(3):389-97.

31. Koninckx PR, Ussia A, Adamyan L, Wattiez A, Donnez J. Deep endometriosis: definition, diagnosis, and treatment. 2012;98(3):564-71.

32. Marcellin L, Santulli P, Bortolato S, Morin C, Millischer AE, Borghese B, et al. Anterior focal adenomyosis and bladder deep infiltrating endometriosis: is there a link? 2018;25(5):896-901.

33. Gordts S, Koninckx P, Brosens I. Pathogenesis of deep endometriosis. Fertil Steril. 2017;108(6):872-85.e1.

34. Exacoustos C, Morosetti G, Conway F, Camilli S, Martire FG, Lazzeri L, et al. New sonographic classification of adenomyosis: do type and degree of adenomyosis correlate to severity of symptoms? J Minim Invasive Gynecol. 2019.

35. Van den Bosch T, de Bruijn AM, de Leeuw RA, Dueholm M, Exacoustos C, Valentin L, et al. Sonographic classification and reporting system for diagnosing adenomyosis. Ultrasound in obstetrics \& gynecology : the official journal of the International Society of Ultrasound in Obstetrics and Gynecology. 2019;53(5):576-82.

36. Lazzeri L, Morosetti G, Centini G, Monti G, Zupi E, Piccione E, et al. A sonographic classification of adenomyosis: interobserver reproducibility in the evaluation of type and degree of the myometrial involvement. 2018;110(6):1154-61.e3.

37. Gordts S, Grimbizis G, Campo R. Symptoms and classification of uterine adenomyosis, including the place of hysteroscopy in diagnosis. Fertil Steril. 2018;109(3):380-8.e1.

38. Bourdon M, Santulli P, Oliveira J, Marcellin L, Maignien C, Melka L, et al. Focal adenomyosis is associated with primary infertility. Fertil Steril. 2020.

39. Tamura H, Kishi H, Kitade M, Asai-Sato M, Tanaka A, Murakami T, et al. Clinical outcomes of infertility treatment for women with adenomyosis in Japan. Reprod Med Biol. 2017;16(3):276-82.

40. Naftalin J, Hoo W, Nunes N, Holland T, Mavrelos D, Jurkovic D. Association between ultrasound features of adenomyosis and severity of menstrual pain. Ultrasound Obstet Gynecol. 2016;47(6):779-83.

41. Iwasawa $\mathrm{T}$, Takahashi $\mathrm{T}$, Maeda $\mathrm{E}$, Ishiyama $\mathrm{K}$, Takahashi $\mathrm{S}$, Suganuma R, et al. Effects of localisation of uterine adenomyosis on outcome of in vitro fertilisation/intracytoplasmic sperm 
injection fresh and frozen-thawed embryo transfer cycles: a multicentre retrospective cohort study. Reproductive biology and endocrinology : RB\&E. 2021;19(1):84.

42. Maubon A, Faury A, Kapella M, Pouquet M, Piver P. Uterine junctional zone at magnetic resonance imaging: a predictor of in vitro fertilization implantation failure. J Obstet Gynaecol Res. 2010;36(3):611-8

43. Naftalin J, Hoo W, Nunes N, Holland T, Mavrelos D, Jurkovic D. The association between ultrasound features of adenomyosis and severity of menstrual pain. Ultrasound in obstetrics \& gynecology : the official journal of the International Society of Ultrasound in Obstetrics and Gynecology. 2015.

44. Gong C, Yang B, Shi Y, Liu Z, Wan L, Zhang H, et al. Factors influencing the ablative efficiency of high intensity focused ultrasound (HIFU) treatment for adenomyosis: a retrospective study. 2016;32(5):496-503.

45. Gong C, Setzen R, Liu Z, Liu Y, Xie B, Aili A, et al. High intensity focused ultrasound treatment of adenomyosis: the relationship between the features of magnetic resonance imaging on T2 weighted images and the therapeutic efficacy. Eur J Radiol. 2017;89:117-22.

46. Keserci B, Duc NM. The role of T1 perfusion-based classification in predicting the outcome of magnetic resonance-guided high-intensity focused ultrasound treatment of adenomyosis. 2018;34(3):306-14.

47. Keserci B, Duc NM. Magnetic resonance imaging features influencing high-intensity focused ultrasound ablation of adenomyosis with a nonperfused volume ratio of $>/=90 \%$ as a measure of clinical treatment success: retrospective multivariate analysis. 2018;35(1):626-36.

48. Naftalin J, Hoo W, Pateman K, Mavrelos D, Foo X, Jurkovic D. Is adenomyosis associated with menorrhagia? 2014;29(3):473-9.
49. Bourdon M, Oliveira J, Marcellin L, Santulli P, Bordonne C, Maitrot Mantelet L, et al. Adenomyosis of the inner and outer myometrium are associated with different clinical profiles. Hum Reprod (Oxford, England). 2021;36(2):349-57.

50. Li T, Xu XX, Dai Y, Zhang JJ, Lang JH, Leng JH. Menorrhagia and uterine volume associated with lower urinary tract symptoms in patients with adenomyosis. Chin Med J (Engl). 2017;130(13):1552-6.

51. Wang F, Shi X, Qin X, Wen Z, Zhao X, Li C. Expression of CD56 in patients with adenomyosis and its correlation with dysmenorrhea. Eur J Obstet Gynecol Reprod Biol. 2015;194:101-5.

52. Orazov MR, Nosenko EN, Radzinsky VE, Khamoshina MB, Lebedeva MG, Sounov MA. Proangiogenic features in chronic pelvic pain caused by adenomyosis. Gynecological endocrinology : the official journal of the International Society of Gynecological Endocrinology. 2016;32(sup2):7-10.

53. Bourdon M, Santulli P, Jeljeli M, Vannuccini S, Marcellin L, Doridot $\mathrm{L}$, et al. Immunological changes associated with adenomyosis: a systematic review. Hum Reprod Update. 2021;27(1):108-29.

54. Seidman JD, Kjerulff KH. Pathologic findings from the Maryland Women's Health Study: practice patterns in the diagnosis of adenomyosis. International journal of gynecological pathology : official journal of the International Society of Gynecological Pathologists. 1996;15(3):217-21.

55. Upson K, Missmer SA. Epidemiology of adenomyosis. Seminars in reproductive medicine. 2020;38(2-03):89-107.

Publisher's Note Springer Nature remains neutral with regard to jurisdictional claims in published maps and institutional affiliations. 